\section{Bilateral Pectoralis Major Tendon Rupture While Performing Intermediate Level Bench Press}

Jace E. Kusler, B.S., MS-4",

Alexander C.M. Chong, MSAE, MSME',2,

Bruce E. Piatt, M.D., ${ }^{1,23}$

${ }^{1}$ University of North Dakota, School of Medicine \& Health

Sciences, Grand Forks, ND

${ }^{2}$ Sanford Health, Department of Graduate Medical

Education, Fargo, ND

${ }^{3}$ Sanford Health, Sanford Orthopedics and Sports Medicine, Fargo, ND

Received Jan. 24, 2019; Accepted for publication March 18, 2019; Published online Aug. 21, 2019

\section{INTRODUCTION}

Simultaneous bilateral pectoralis major (PM) tendon rupture is a rare injury. To our knowledge, there have been only three previously reported cases of this type of injury. ${ }^{1-3}$ These patients sustained the injury while attempting a $360^{\circ}$ turn on gymnastic rings, ${ }^{1}$ bench-pressing a heavier-than-normal load without an appropriate warm-up period, ${ }^{2}$ and performing dips on wide-grip parallel bars. ${ }^{3}$ We present a case of a patient who sustained simultaneous bilateral PM tendon ruptures while performing intermediate level bench-pressing with an appropriate warm-up period.

\section{CASE REPORT}

A 37-year-old, right-hand dominant male (height: $180 \mathrm{~cm}$; weight: $83.5 \mathrm{~kg}$; BMI: $25.7 \mathrm{~kg} / \mathrm{m} 2$ ) presented with a chief complaint of bilateral shoulder pain for two days since performing a fitness test to develop a weight lifting program. While testing his intermediate level bench press, he started at 200 pounds, then increased the weight to 215 pounds (1.17 times of his bodyweight). At that time, he felt a "pop" during the eccentric phase along with pain in the anterior aspect of the shoulders bilaterally. He immediately stopped all activities. He noticed pain in both shoulders while trying to raise his arms in forward flexion, but he felt his right shoulder hurt worse than his left shoulder. He denied any pain at rest, current or past significant medical issues, prescription medications, or steroid or illicit drug use.

On physical examination, the patient was intact neurovascularly, with ecchymosis over the anterior upper arms, and flattening of the anterior axillary folds bilaterally. Active forward flexion of his shoulders was limited to $60^{\circ}$ bilaterally due to pain, external rotation was $80^{\circ}$ bilaterally, and internal rotation was to T10 bilaterally. He had 5 of 5 strength bilaterally other than 4 of 5 strength of adduction bilaterally. The patient had normal belly press and lift off tests.

Magnetic resonance imaging (MRI) scans were obtained for both shoulders, and he was diagnosed with bilateral tears of the PM sternal head. They were torn at the bone insertion with moderate retraction bilaterally (Figure 1). Treatment options such as non-operative management, operative with simultaneous surgical repair, and operative with a staged surgical repair were discussed with the patient. The patient did not want to undergo simultaneous repair due to the difficulties with activities of daily living that would occur during recovery;

\section{KANSAS JOURNAL of MEDICINE}

therefore, he chose staged repair as he wanted to be active in the future with no limitations.
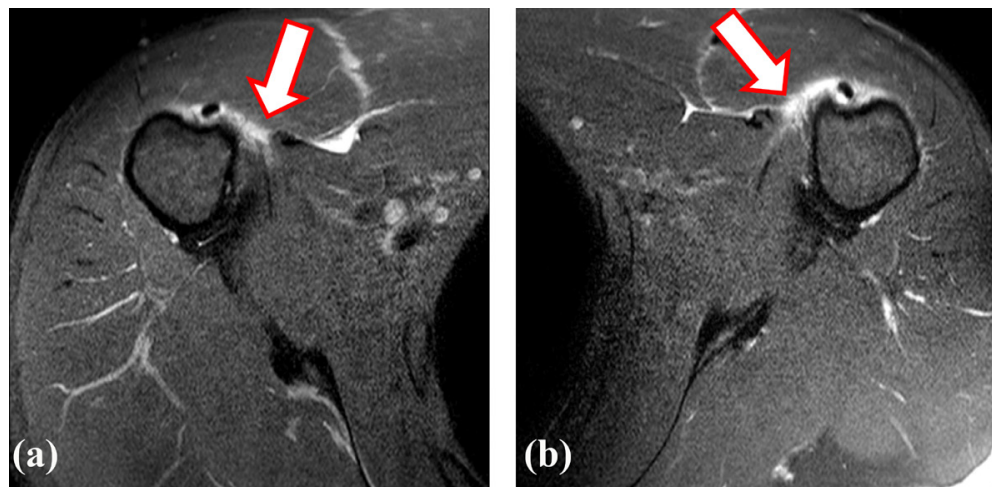

Figure 1. Magnetic resonance imaging of patient's shoulder showing complete rupture of the pectoralis major tendon: (a) right shoulder and (b) left shoulder.

The patient underwent right PM tendon repair first at six days post-injury, then left PM tendon repair at six weeks post-injury. In both instances, the patient was put in a "beach chair" position, and was under general anesthesia with an interscalene block. Surgery was performed through a deltopectoral incision, and complete rupture of the pectoralis major tendon was found on both shoulders. The repair used two suture anchors with No. 2 FiberWire (5.5 mm Bio-Corkscrew anchor, Arthrex Inc., Naples, FL) that were spaced evenly in the intertubercular sulcus of the humerus. A mattress stitch through the end of the PM tendon and standard surgical knots were used to secure the repair. There were no intraoperative complications for either procedure.

Postoperatively, each affected shoulder was placed into a shoulder immobilizer in adduction and internal rotation, with pendulum exercises of the shoulder along with elbow, wrist, and hand motion exercises for two weeks. At two-weeks postoperatively, the patient began physical therapy with passive range of motion allowing internal rotation and forward elevation as tolerated for two weeks; however, external rotation was limited to $30^{\circ}$ maximum. At four-weeks postoperatively, the patient was allowed full passive range of motion in all planes. At six weeks postoperatively, active range of motion as tolerated and isometric strengthening exercises were started, and progressive resistive exercises started at 10-weeks postoperatively. The patient was permitted to begin strengthening the shoulder with dumbbells as tolerated at four months postoperatively. The patient was restricted from sports until six months postoperatively, at which time he was allowed to return to all activities as tolerated.

At the latest follow-up evaluation (right shoulder: six months; left shoulder: four months, three weeks postoperatively), the patient had symmetric active range of motion of $175^{\circ}$ of forward flexion, $70^{\circ}$ of external rotation, and internal rotation to T8. The patient had 5 of 5 strength bilaterally and normal cosmesis to the anterior axillary fold. Overall, the patient was extremely satisfied with the results of the surgical procedures. 
KANSAS JOURNAL of MEDICINE

BILATERAL PECTORALIS MAJOR TENDON RUPTURE continued.

\section{DISCUSSION}

Pectoralis major tendon rupture occurs almost exclusively (29\% - 70\%) in weight-lifting athletes during supine bench press exercises. ${ }^{4-14} \mathrm{~A}$ unilateral PM tendon rupture is a rare injury, which usually occurs when the arm is extended and externally rotated with sudden overloading of a maximally contracted muscle during bench pressing. Bilateral PM tendon rupture is rare as there only have been three previously reported cases. The case reported by Valeriote et al. ${ }^{2}$ was due to bench-pressing a heavier-than-normal load without an appropriate warm-up period. This is the second reported case of simultaneous bilateral PM rupture while performing intermediate level bench pressing.

The case reported by Valeriote et al. ${ }^{2}$ and this case were similar in that during the eccentric-loading phase of bench pressing, the patients had either a tearing or a "pop" sensation in the anterior aspects of their shoulders with simultaneous axillary pain. Deformities of PM tendon were noticed as well as ecchymosis, and bilateral weakness of adduction and internal rotation upon physical examination. Both of these patients were diagnosed with bilateral PM tendon rupture and elected to undergo staged surgical repair.

Misdiagnosis of a bilateral PM tendon rupture can occur, especially for the inexperienced physician or physician assistant. A comprehensive history and physical examination are very important in diagnosis of a bilateral PM tendon rupture, however, MRI imaging modalities are recommended especially in confusing cases. Upon taking the history, patients often report a tearing sensation or hearing a "pop" followed by sudden pain at the medial aspect of the upper arm, deformity, weakness, and swelling. Physical examination typically consists of a palpable defect, tenderness over the humeral insertion, an asymmetric axillary fold, weakness in shoulder adduction and internal rotation, and occasionally ecchymosis. ${ }^{15-17}$ The swelling and discoloration down the arms can be mistaken for a proximal biceps injury instead of PM rupture. A MRI, however, can offer a reliable method for diagnosing the injury and it is the best imaging modality to determine extent and location of a rupture. ${ }^{18}$

Treatment decisions frequently depend on determination of complete versus partial tears of the PM tendon, the patient's age, and the functional status of the patient, as the PM tendon is not required for most activities of daily living. ${ }^{19-20}$ Treatment consists of nonoperative versus operative management. Non-operative treatment generally is recommended for contusions, partial tears, muscle belly ruptures, and complete tears for lower-demand or sedentary individuals. ${ }^{17}$ In most cases, these patients will resume full activities of daily living. Late surgical repair or reconstruction, however, may be considered if the patient fails to progress over the first three to four months. Operative treatment is favorable in all young active patients regardless of the chronicity of injury, as surgical repair provides the best outcomes in satisfaction, pain relief, restoration of pre-injury strength and function, superior cosmetic results, and ability to return to sport. ${ }^{10,15-17,21-23}$ Various fixation techniques, such as beach chair versus supine positions through a deltopectoral or anterior axillary approach, tendon-to-tendon, bone trough, suture anchors, cortical buttons, and staged versus simultaneous tendon repairs have been used to reattach the PM tendon to its normal humeral insertion site. ${ }^{3,22}$ Simultaneous bilateral PM tendon repairs have significant limitations compared to a staged repair, such as the inability to drive and perform certain activities of daily living that require external rotation of a shoulder for at least three weeks. ${ }^{1}$ However, Zvijac et al. ${ }^{1}$ recommended certain techniques such as the "through the legs" technique for perineal care to help patients complete some activities of daily living during the recovery period. Delayed diagnosis can result in the need for allograft reconstruction rather than direct repair, which in turn may have less favorable outcomes. ${ }^{24}$

Bilateral PM tendon rupture is a rare injury, and the point of emphasis from this case is to have a high index of suspicion for patients presenting with bench pressing induced chest or shoulder pain/injury even if the concerned shoulder is only a unilateral injury. Awareness of the potential for misdiagnosis of biceps tendon injury could make surgical repair easier and lower the complication rates.

\section{ACKNOWLEDGEMENT}

Verbal consent was obtained from the patient granting permission that data concerning his case could be submitted for publication.

\section{REFERENCES}

${ }^{1}$ Zvijac JE, Gampel B, Kiebzak GM. Simultaneous bilateral rupture of the pectoralis major tendons while exercising on the rings. Curr Orthop Pract 2011; 22(4):376-8.

${ }^{2}$ Valeriote J, Purchase RJ, Kelly JD. Simultaneous bilateral pectoralis major muscle rupture. Am J Orthop (Belle Mead NJ) 2005; 34(6):301302. PMID: 16060560.

${ }^{3}$ Potter BK, Lehman RA Jr, Doukas WC. Simultaneous bilateral rupture of the pectoralis major tendon. A case report. J Bone Joint Surg AM 2004; 86-A(7):1519-21. PMID: 15252102.

${ }^{4}$ de Castro Pochini A, Ejnisman B, Andreoli CV, et al. Pectoralis major muscle rupture in athletes: A prospective study. Am J Sports Med 2010; 38(1):92-8. PMID: 19880715.

${ }^{5}$ Schepsis AA, Grafe MW, Jones HP, Lemos MJ. Rupture of the pectoralis major muscle. Outcome after repair of acute and chronic injuries. Am J Sports Med 2000; 28(1):9-15. PMID: 10653537.

6 Ohashi K, El-Khoury GY, Albright JP, Tearse DS. MRI of complete rupture of the pectoralis major muscle. Skeletal Radiol 1996; 25(7):625628. PMID: 8915045.

7 Simonian PT, Morris ME. Pectoralis tendon avulsion in the skeletally immature. Am J Orthop (Belle Mead NJ) 1996; 25(8):563-564. PMID: 8871755.

${ }^{8}$ Alho A. Ruptured pectoralis major tendon. A case report on delayed repair with muscle advancement. Acta Orthop Scand 1994; 65(6):652-653. PMID: 7839855 .

9 Rijnberg WJ, van Linge B. Rupture of the pectoralis major muscle in bodybuilders. Arch Orthop Trauma Surg 1993; 112(2):104-105. PMID: 8457408.

${ }^{10}$ Liu J, Wu JJ, Chang CY, Chou YH, Lo WH. Avulsion of the pectoralis major tendon. Am J Sports Med 1992; 20(3):366-368. PMID: 1636872.

${ }^{11}$ Wolfe SW, Wickiewicz TL, Cavanaugh JT. Ruptures of the pectoralis major muscle. An anatomic and clinical analysis. Am J Sports Med 1992; 20(5):587-593. PMID: 1443329.

${ }^{12}$ Hodgkinson DJ. Chest wall deformities and their correction in bodybuilders. Ann Plast Surg 1990; 25(3):181-187. PMID: 2241034.

13 Roi GS, Respizzi S, Dworzak F. Partial rupture of the pectoralis major muscle in athletes. Int J Sports Med 1990; 11(1):85-87. PMID: 2318568.

${ }^{14}$ Kretzler HH Jr, Richardson AB. Rupture of the pectoralis major muscle. Am J Sports Med 1989; 17(4):453-458. PMID: 2782527.

${ }_{15}$ Neumann JA, Klein CM, van Eck CF, Rahmi H, Itamura JM. Outcomes after dermal allograft reconstruction of chronic or subacute pectoralis major tendon ruptures. Orthop J Sports Med 2018; 6(1):2325967117745834. PMID: 29318178. 
${ }^{16}$ Butt U, Mehta S, Funk L, Monga P. Pectoralis major ruptures: A review of current management. J Shoulder Elbow Surg 2015; 24(4):655-662. PMID: 25556808

${ }^{17}$ Haley CA, Zacchilli MA. Pectoralis major injuries: Evaluation and treatment. Clin Sports Med 2014; 33(4):739-756. PMID: 25280620.

${ }^{18}$ Chiavaras MM, Jacobson JA, Smith J, Dahm DL. Pectoralis major tears: Anatomy, classification, and diagnosis with ultrasound and MR imaging. Skeletal Radiol 2015; 44(2):157-164. PMID: 25200915.

${ }_{19}$ Beloosesky Y, Grinblat J, Weiss A, Rosenberg PH, Weisbort M, Hendel D. Pectoralis major rupture in elderly patients: A clinical study of 13 patients. Clin Orthop Relat Res 2003; (413):164-169. PMID: 12897606

20 Zeman SC, Rosenfeld RT, Lipscomb PR. Tears of the pectoralis major muscle. Am J Sports Med 1979; 7(6):343-347. PMID: 507270.

${ }^{21}$ Merolla G, Paladini P, Campi F, Porcellini G. Pectoralis major tendon rupture. Surgical procedures review. Muscles Ligaments Tendons J 2012; 2(2):96-103. PMID: 23738281

${ }^{22}$ Provencher MT, Handfield K, Boniquit NT, Reiff SN, Sekiya JK, Romeo AA. Injuries to the pectoralis major muscle: Diagnosis and management. Am J Sports Med 2010; 38(8):1693-1705. PMID: 20675652.

${ }^{23}$ Dunkelman NR, Collier F, Rook JL, Nagler W, Brennan MJ. Pectoralis major muscle rupture in windsurfing. Arch Phys Med Rehabil 1994; 75(7):819-821. PMID: 8024433

${ }^{24}$ Schachter AK, White BJ, Namkoong S, Sherman O. Revision reconstruction of a pectoralis major tendon rupture using hamstring autograft: A case report. Am J Sports Med 2006; 34(2):295-298. PMID: 16170043.

Keywords: pectoralis muscles, tendon injury, shoulder pain, orthopedic surgical procedures, sports

\section{KANSAS JOURNAL of MEDICINE} BILATERAL PECTORALIS MAJOR TENDON RUPTURE continued. 